\title{
La Ciencia de lo Sustentable: Razón de Ser del Discurso Funcional en Ecología
}

\author{
Gustavo Caponi \\ $\mathrm{CNPq}$ /Universidade Federal de Santa Catarina
}

\begin{abstract}
The main cognitive target of Ecology is the functional analysis of the ecological processes and systems. It does not suppose, meanwhile, that these processes and systems are designed systems and processes like individual leaving beings. The Ecology, likewise Physiology, is constitutively guided by the presupposition of a privileged state, to be explained, that it is the persistence of the systems and processes that she studied; and its functional analyses obey to this presupposition. Ecology supposes an ideal of natural order, under which consideration this privileged state is thinking as an improbable state of things and, for that, needed of explanation; and, in what concerns this latter point, the analogy between Ecology and Physiology can also result instructive.
\end{abstract}

Keywords: Design, function, functional imputation, ideal of natural order, privileged state.

\section{Presentación}

La ubicuidad del discurso funcional en Ecología hace pensar que, en esta disciplina, la preservación, o la generación, de ciertos procesos u ordenamientos particulares, ocupa un lugar análogo a aquel ocupado por la preservación y la generación del organismo individual en la Fisiología; y eso permite que nos preguntemos si allí está o no implicada una insostenible representación organicista de los sistemas ecológicos. Esta representación, más o menos temperada, tuvo, al final de cuentas, muchos defensores y ella ejerció una marcada gravitación en la historia de la Ecología. ${ }^{1}$ Por eso, la ubicuidad del discurso funcional que, según digo, caracteriza a esa disciplina, podría ser vista como el resabio, ilegítimo y en última instancia pernicioso, de ese modo organicista de entender a las poblaciones, a las comunidades y a los ecosistemas.

Sin embargo, una cosa es afirmar que la Ecología analiza los sistemas y procesos que van más allá de los fenómenos analizados por la Autoecología ${ }^{2}$ refiriéndolos siempre algo que, en cierto sentido, podría ser considerado como un estado privilegiado (cf. Rosenfeld 2002, p.157; El-Hani \& Nunes 2009, p.71); y otra cosa diferente es afirmar que los ecólogos piensen esos sistemas y procesos, que están por encima del viviente individual, como si ellos también fuesen totalidades orgánicas, o partes de tales totalidades. Lo primero, como espero poder mostrar, no implica necesariamente lo segundo; $y$ es justamente esa referencia permanente, y constitutiva, a estados privilegiados, y no una representación organicista de los sistemas y procesos ecológicos,

Principia 14(3): 349-373 (2010).

Published by NEL — Epistemology and Logic Research Group, Federal University of Santa Catarina (UFSC), Brazil. 
la que explica que la Ecología, al igual que la Fisiología, también sea una disciplina pautada por una perspectiva eminentemente funcional que queda plasmada en su discurso y en sus conceptos fundamentales.

Ambas disciplinas, la Ecología y la Fisiología, diré aquí, consideran los fenómenos por ellas estudiados en virtud de la oposición orden improbable-desorden probable; y es en el marco de esa polaridad, pasible de ser entendida recurriendo a la noción de ideal de orden natural propuesta por Toulmin (1961), que debe situarse la referencia a estados privilegiados que da su legitimidad definitiva y su razón de ser más profunda a la perspectiva funcional propia de la Ecología. Pero, antes de proceder a la elucidación y clarificación de esa referencia a estados privilegiados, que digo ser constitutiva de la Ecología, me detendré a analizar algunos aspectos particulares del discurso funcional de esta disciplina, intentando mostrar que él tampoco presupone que los sistemas y procesos ecológicos deban, o puedan, ser considerados como sistemas y procesos que, a la manera de los vivientes individuales y algunos de sus atributos, merezcan el calificativo de [naturalmente] diseñados.

Así, basándome en una concepción sistémica, o procesal, del concepto de función (Caponi 2010a), y delineando, a partir de ésta, una definición puramente naturalista del concepto de diseño (Caponi 2010b), ensayaré una primera y parcial clarificación de la legitimidad y de la razón del ser del discurso funcional en Ecología. Y este primer análisis será luego complementado por la elucidación de esa referencia tácita, pero permanente, a estados privilegiados que, según sostengo, constituye la razón de ser más profunda y definitiva de ese discurso funcional. El problema central de la Ecología, diré entonces, es explicar cómo es que ciertos procesos y ordenamientos de la biosfera se sostienen, y se repiten, pese a su relativa improbabilidad; y es en el marco de esa preocupación por el sostenimiento y la reiteración de lo improbable, que los diferentes subprocesos y elementos que integran dichos procesos y estados de cosas mayores, son analizados, buscando identificar su contribución causal, su función, en la sustentación y en la eventual recurrencia de esos últimos.

\section{Dos consideraciones preliminares}

No existe una esencial desemejanza entre la metáfora y lo que los profesionales de las ciencia nombran la explicación de un fenómeno. Ambas son una vinculación tramada entre dos cosas distintas, a una de las cuales se le trasiega en la otra. Ambas son igualmente verdaderas o falsas. Jorge Luís Borges, La Metáfora.

Si se acepta la concepción sistémica de función, y se deja de lado la sedicente concepción etiológica de dicho concepto (cf. Caponi 2010a, p.52-5), se debe aceptar tam- 
bién que todo proceso o sistema complejo puede ser funcionalmente analizado (cf. Caponi 2010a, p.61; 2010b, p.80). ${ }^{3}$ Siempre se pueden discriminar subprocesos o subsistemas más simples al interior de ese proceso o sistema más complejo, mostrando cómo es que los primeros intervienen en la ocurrencia o en el funcionamiento de estos últimos (cf. Cummins 1975, p.762). Por eso, asumiendo esa idea, la ocurrencia de análisis funcionales particulares en cualquier dominio de investigación no tiene por qué resultar algo muy sorprendente o problemático. Más aun: yo diría, incluso, que una medida, epistémica o metodológica, de la complejidad de cualquier sistema o proceso, sea él natural o social, es la relevancia o la utilidad, y no la legitimidad, que en su estudio pueda tener el uso de análisis funcionales.

Cualquier proceso o sistema puede ser funcionalmente analizado (Ponce 1987, p.106); pero no en todos los casos ese análisis será igualmente relevante o útil. Se puede decir que un aumento de la densidad del líquido en el que flota un cuerpo, tuvo una función, un papel causal, en el incremento del empuje padecido por ese cuerpo; pero eso es sólo un corolario inmediato de lo que un conocimiento nomológico ya disponible permite dar como explicación causal de dicho fenómeno: en esa imputación funcional no parece haber ningún lucro cognitivo efectivo. En cambio, en el estudio de un proceso causal más complejo, como puede serlo una catástrofe aérea, confirmar que el uso de teléfonos celulares por parte de los pasajeros tuvo, efectivamente, una función, un papel causal, en la falla de un sistema del avión siniestrado, sí que constituiría un alarmante logro cognitivo.

En ese caso, aunque la interferencia de la señal de celular en el circuito del sistema afectado fuese un fenómeno al cual finalmente le pudiésemos dar una explicación física fundada en leyes ya conocidas, la hipótesis de que esa interferencia podía existir, y de que ella era capaz de desencadenar un accidente, no se derivaría inmediatamente de ninguna ley o teoría preestablecida; y también es muy posible que ella tampoco fuese fácilmente deducible de nuestro conocimiento previo sobre el funcionamiento de los celulares y del sistema afectado en el avión siniestrado. Evidentemente, la corroboración de ese papel causal del uso de celulares en el accidente ocurrido, es decir, la justificación de esa imputación funcional, sí acarrearía un lucro cognitivo efectivo. Por eso, cuando el conjunto de condiciones antecedentes de un fenómeno es muy complejo, y cuando no se cuenta con un conocimiento nomológico bien delimitado que nos permita determinar y discriminar cuáles fueron efectivamente los papeles causales de esas condiciones antecedentes en la ocurrencia de dicho fenómeno, siempre somos llevados a razonar funcionalmente. Aunque, después, traduzcamos nuestras conclusiones en un lenguaje que elida toda imputación funcional.

Pero una cosa es el hecho de que, en un dominio cualquiera de investigación cualquiera, se puedan dar análisis funcionales particulares, como aquel que el geólogo realiza cuando le atribuye una función, un papel causal, a la erosión hídrica 
en la formación de una quebrada; y otra cosa es el hecho que toda una disciplina, como es el caso de la Fisiología, esté ordenada, toda ella, por una perspectiva funcional: eso nos indica algo sobre los objetivos cognitivos específicos de ese dominio de investigación. La Fisiología, como ya lo sabía Claude Bernard (1878, p.371), es, fundamentalmente, una ciencia de funciones (cf. Keller 2010, p.27). Su objetivo cognitivo específico no reside tanto en conocer las causas antecedentes de los fenómenos orgánicos, sino más bien en determinar sus funciones, sus papeles causales, sus efectos, en la preservación de ese sistema que es el organismo individual (Goldstein 1951, p.339; Caponi 2007a, p.449). La Fisiología es la ciencia del ciclo vital; y su objetivo primigenio es conocer cómo las diferentes estructuras y procesos orgánicos contribuyen causalmente a la realización de ese ciclo (Caponi 2010b, p.83).

Sin embargo, y como ya lo observé en la presentación, lo que vale para la Fisiología también parece valer, de algún modo y en alguna medida, para la Ecología. Conceptos tan fundamentales para ella, como lo son los de organismos productores, organismos consumidores y organismos descomponedores, son, todos ellos, de naturaleza eminentemente funcional: ellos aluden fundamentalmente al papel causal de esos organismos en el funcionamiento de un ecosistema (cf. Odum 1988 p.13); y lo mismo ocurre con otros conceptos menos generales, como el de predador o el de polinizador (cf. Gayon 2010, p.134). Estos últimos aluden a la función de una población dentro de una comunidad biótica (cf. Sergio et al. 2008; Tilman et al. 2008). Allí, caracterizar una especie como polinizadora no implica querer indicar que ella viva de la polinización; porque, de hecho, ninguna especie lo hace. Decir que una especie es polinizadora implica atribuirle una función dentro del proceso de polinización de otra $u$ otras especies.

Pero esa perspectiva funcional que atraviesa y ordena el discurso de la Ecología, se hace más evidente todavía en una noción como la de redundancia funcional (cf. Rosenfeld 2002). Ésta alude, justamente, al hecho de que dos poblaciones de especies diferentes pueden desempeñar el mismo papel, o papeles muy semejantes, en funcionamiento de la comunidad, o del ecosistema, que ambas integran (Ricklefs 2003, p.449; El-Hani \& Almeida 2006, p.34; Gayon 2010, p.134). Así, si una de ellas desaparece de ese sistema, o su número decrece, su función puede cumplida por la otra; y eso permite pensar, incluso, en la posibilidad de que la extinción de ciertas especies en algunos ecosistemas pueda ser compensada por la importación de especies funcionalmente análogas (cf. Donlan et al. 2006; Donlan 2010).

Pero, aunque el lenguaje funcional sea moneda corriente en la Ecología, su legitimidad, como dije en la presentación, puede generar dudas y resistencias: se podría pensar que se trata únicamente de simples maneras de hablar, un tanto equívocas, que, si resultan difíciles de evitar, seria mejor no tomarlas muy seriamente; y creo que, además de la asociación entre discurso funcional y organicismo, otro de los motivos principales de las suspicacias suscitadas por el discurso funcional de la Eco- 
logía, reside en el hecho de que se tiende a asociar, y hasta confundir, análisis funcionales con atribuciones de diseño. Pero, si consideramos que sólo cabe hablar de diseño cuando una estructura evolucionó en virtud de un proceso que premió un incremento de su eficacia funcional, esa asociación no tiene por qué ser hecha; y creo que ése es, claramente, el caso de los elementos que componen un sistema ecológico. Ellos pueden ser funcionalmente analizados, e incluso funcionalmente comparados en términos de eficiencia, sin que eso implique la presunción de que los mismos han sido diseñados en virtud del cumplimiento de las funciones que a ellos les atribuimos.

\section{Función, diseño y efectividad}

Es importante, por eso, que se pueda dar una definición precisa, pero al mismo tiempo general, de lo que hemos de entender por objeto diseñado; y creo que ella podría ser la siguiente: $X$ es un objeto diseñado en la medida en que alguno de sus perfiles sea el resultado de un proceso de cambio pautado por incrementos en la eficiencia con la que ese perfil cumple una función dentro de él (cf. Caponi 2010b, p.93); y lo que puede entenderse por función es, simplemente, el papel causal que algo cumple en el desarrollo de cualquier proceso causal o en el funcionamiento de cualquier sistema (cf. Cummins 1975; Caponi 2010a). Pero, aunque esta definición de función sea sumamente amplia y tolerante, el concepto de objeto diseñado que puede delinearse a partir de ella ciertamente no lo es.

Según este modo de entender el concepto de función, y como ya lo apunté en la sección anterior, cualquier proceso causal puede ser analizado funcionalmente, imputando a cada uno de sus elementos un papel causal en su desarrollo; y, a este respecto, la actitud radical de Margarita Ponce (1987, p.106) me parece la más correcta y coherente. Según ella, en un análisis funcional, la entidad funcional "es, simplemente, el fenómeno o el hecho que comprendemos en virtud de sus consecuencias en cada caso de explicación; y la función es el efecto de la cosa funcional que contribuye a la consecución del estado de cosas o del fenómeno por cuyas causas inquirimos en ese mismo proceso explicativo". Aunque yo, particularmente, preferiría expresar esa misma idea diciendo que, en un análisis funcional, el ítem funcional no es otra cosa que el fenómeno o elemento cuya contribución o intervención en la ocurrencia de un proceso particular queremos entender o destacar; y la función es la contribución o intervención de dicha entidad en el mencionado proceso. Nuestro análisis privilegia un estado de cosas o un proceso como merecedor de explicación; $\mathrm{y}$, a partir de ahí, sus condiciones de ocurrencia son pensadas en virtud de su papel causal, de su función, en su sostenimiento u ocurrencia.

Donde haya explicaciones causales, podríamos así decir, habrá siempre análisis y atribuciones funcionales posibles; porque esos análisis y esas imputaciones, como

Principia 14(3): 349-373 (2010). 
de algún modo también lo dice Margarita Ponce (1987, p.103), no son más que el reverso de esas explicaciones y atribuciones causales. Pero, aunque todo proceso causal y todo sistema pueda ser funcionalmente analizado, y he aquí una obviedad que no siempre es tenida en cuenta, únicamente de algunos procesos y de algunos sistemas muy particulares puede decirse que han estado sometidos a procesos de cambio pautados por incrementos progresivos en la eficacia con la que algunos de sus elementos cumple un papel en su funcionamiento.

La luna, por ejemplo, cumple una función en el movimiento de las mareas: ella tiene un papel causal en ese proceso. Pero nada en la luna se ha modificado en virtud de un mejor cumplimiento de dicha función; ni tampoco ella esta ahí en virtud de esa función: regular el movimiento de las mareas no es la razón de ser de la luna. ${ }^{4}$ Por eso no la consideramos como un objeto diseñado. Por otro lado, aunque al escoger piedras para "hacer sapitos" en un estaque, constatemos que las aplanadas son más convenientes para el cumplimiento de esa función que las más esféricas, tampoco diremos que aquellas son objetos diseñados: sus perfiles fueron modificados por agentes físicos que nada tenían que ver con el cumplimiento de esa u otra función (Caponi 2010b, p.91). Muy distinto es lo que ocurre, en cambio, con los dispositivos técnicos construidos por agentes intencionales, como los seres humanos, y con las características de los seres vivos que han sido modeladas por la selección natural.

En el primer caso, las funciones en cuestión son los papeles que esos objetos cumplen en los procesos para cuya realización ellos fueron construidos o adoptados; y así diremos que un hacha paleolítica es un objeto diseñado en la medida en que sus perfiles fueron modificados para mejor cumplir con la función de cortar o golpear. $\mathrm{O}$ diremos que una semilla cultivable es un objeto diseñado en la medida en que sus perfiles responden a un proceso de hibridación, de selección artificial o de manipulación genética, tendiente a incrementar su rendimiento en un determinado suelo o su resistencia a una plaga. Mientras tanto, en el caso de seres vivos no sometidos a ninguno de estos últimos procesos, diremos que ellos están diseñados en la medida en que sus perfiles se modificaron, por selección natural, en virtud de que dichas modificaciones permitían el mejor cumplimiento de alguna función biológica; y por función biológica no debemos entender otra cosa que el papel causal que las estructuras o fenómenos orgánicos cumplen en la realización del ciclo vital de un determinado organismo (Caponi 2010a, p.62; 2010b, p.83).

Este concepto de función biológica es, en efecto, un caso particular de la noción sistémica o procesal de función propuesta por Cummins (1975). Se trata simplemente de una versión específica de esta última noción que sería propia de las ciencias biológicas. Según la misma, decir que $Y$ es la función biológica de $X$ en $Z$ supone: [1] que $Z$ es el ciclo vital de un ser vivo; [2] que $X$ produce $Y$; y [3] que $Y$ tiene un papel causal en la realización de $Z$. Así, todo $X$ tal que tenga un efecto $Y$ que contribuya para que un organismo se preserve, se desarrolle y se reproduzca en un ambiente 
determinado, podrá ser descrito como poseyendo una función; y ésta no será otra que la contribución de $X$ al cumplimiento de esa preservación, de ese desarrollo y de esa reproducción (cf. Caponi 2010a, p.59 y ss; 2010b, p.79 y ss).

Pero, insisto, en que poseer una función no es lo mismo que estar diseñado o que tener una razón de ser. Para que un ítem funcional pueda ser descrito como diseñado, o como poseyendo una razón de ser, es necesario que sus perfiles, como ya dije, se hayan modificado en virtud de un cumplimiento más eficiente de alguna función por él desempeñada. Por eso, aunque un elemento o característica orgánica pueda cumplir una función en el ciclo vital de un organismo, no se dirá que ella está diseñada para dicha función hasta tanto no se compruebe que la misma se ha modificado en virtud de un cumplimiento más eficaz de su papel causal al interior de ese ciclo vital (Caponi 2010b, p.95).

Incidentalmente, el olor que produce una planta al metabolizar una sustancia tóxica que está contaminando el terreno en la que ella crece, puede ayudarla a ahuyentar unos insectos que acaban de invadir la región; y entonces podrá decirse que ese olor acabó teniendo una función importante en el ciclo vital de la planta. Pero, aunque sea así, no podremos decir que la capacidad de producir ese olor sea una característica diseñada. Dicha capacidad no surgió como respuesta a la presión ejercida por la plaga. Ella, aunque útil como protección, no es una adaptación para el cumplimiento de dicha función; y esto nos coloca ante la relación indisoluble que existe entre diseño biológico y selección natural.

Un perfil orgánico es un perfil [naturalmente] diseñado, es una adaptación, si y sólo si, él ha sido modificado por selección natural en virtud de que dicha modificación permitía un cumplimiento más efectivo de alguna función biológica. Es decir: se puede caracterizar a una estructura orgánica $X$ como estando [naturalmente] diseñada para hacer $Y$, si y sólo si, se cumplen las siguientes condiciones: [1] $Y$ es una función biológica de $X, \mathrm{y}$ [2] $X$ es el resultado de un proceso de cambio (anatómico o comportamental) de estructura producido por la selección natural en virtud de que $X$ haya sido mas eficiente en la realización de $Y$ que sus variantes alternativas (cf. Allen \& Bekoff 1998, p.578; Caponi 2010b, p.94).

Nótese, por otra parte, que la propia noción de eficiencia en el cumplimiento de una función también es anterior a [e independiente de] la de diseño. Podemos decir que los cantos rodados aplanados son más eficientes para hacer sapitos que los arredondeados; y eso tampoco implica que dichas piedras hayan sido modeladas para esa noble función. Y también podemos decir que la sustancia olorosa producida por una planta al metabolizar una sustancia tóxica que está contaminando el terreno en la que ella crece, es más eficiente para ahuyentar unos insectos que acaban de invadir la región, que la producida por otra planta que también crece allí, sin que eso conlleve la suposición de que el efecto protector de esa excreción haya sido premiado o acentuado por la selección natural. De hecho, para que la propia selección natural 
pueda ocurrir, es necesario que a ella le preexistan diferencias de eficiencia en el modo en el que distintas variantes heredables de una estructura al interior de una población, permiten desempeñar una determinada función (Caponi 2010b, p.88); y, por eso mismo, para que las explicaciones seleccionales puedan ser construidas es necesario que esas diferencias sean previamente conocidas (Caponi 2010a, p.67). Las imputaciones funcionales y las comparaciones de eficacia preexisten a las explicaciones seleccionales.

Lo que ocurre, en realidad, es que la noción de eficiencia es sólo un caso particular de la noción de efectividad. Las piedras aplanadas son más efectivas que las arredondeadas en la producción de 'sapitos'; y la sustancia producida por una planta es más efectiva como repelente de insectos que la producida por otra. El veneno de una víbora, por otro lado, puede ser más efectivo que el de otra víbora; y dependiendo del punto de vista en que nos pongamos, describiremos esa mayor efectividad como mayor eficiencia o como mayor peligrosidad. Pero, en ambos casos, estaremos diciendo básicamente lo mismo: estaremos comparando la efectividad de dos elementos en la producción de un determinado proceso causal o en la producción de procesos causales similares. $\mathrm{Y}$ algo semejante ocurre con expresiones como, 'más dañoso que', 'más perjudicial que', 'más nocivo que' o 'más pernicioso que'.

Si alguien dice que, en lo atinente al desarrollo de ciertos tumores cancerosos, un agroquímico producido por la Monsanto es más perjudicial que su análogo producido por la Bayer, esa afirmación puede traducirse, sin perdida ni agregado de significado o información, diciendo que, por lo menos en lo que atañe a esos tumores, el agroquímico de Monsanto es un cancerigeno más efectivo que el agroquímico de Bayer. Los dos agroquímicos, estamos suponiendo, pueden tener una función, un papel causal, en el surgimiento de ciertos tumores; pero a ese respecto, uno de ellos, según estamos diciendo, es más efectivo, o más dañoso, que el otro. Él desencadena los daños y reacciones que pueden llevar al surgimiento de un tumor, con mayor frecuencia, rapidez e intensidad que su competidor en el mercado. Pero todo eso no quiere decir, claro, que ambos productos hayan sido diseñados para cumplir esa función cancerigena: ellos fueron diseñados para matar yuyos que comprometían determinados cultivos; y sus componentes químicos fueron inocentemente elegidos para el mejor cumplimiento de esa función herbicida. ${ }^{5}$

De lo dicho hasta aquí también se puede extraer, por otra parte, una definición de proceso de diseño: éste es justamente un proceso orientado por la detección y refuerzo de la efectividad del desempeño funcional de un elemento al interior de un sistema. La erosión hídrica que modela los cantos rodados haciéndolos progresivamente más adecuados para su uso como proyectiles no es, en este sentido, un proceso de diseño: él no registra ese incremento en el posible desempeño de las piedras como proyectiles, ni tampoco se orienta por su progresiva acentuación. Y tampoco es un proceso de diseño el incremento de la humedad del aire que aumenta su capacidad 
de conducir descargas eléctricas. El aire funciona como conductor de esas descargas, y el incremento de la humedad aumenta esa conductividad; pero, dicho incremento de la humedad, no estuvo ni pautado, ni ordenado, ni orientado, bajo ningún punto de vista, por ese aumento de la eficiencia del aire en el desempeño de su habitual función conductora.

El tallado de una piedra, hecho por un hombre para hacer de ella un hacha, sí es, en cambio, un proceso de diseño: el tallador va escogiendo perfiles de la piedra que puedan prestarse a la forma y uso que el quiere darle a esa herramienta, y él los va modelando para mejor adecuarlos a dicho uso. Pero, aunque eso sea, evidentemente, un proceso de diseño, la producción accidental de lascas de piedra que se van desprendiendo de la pieza que está siendo tallada, no lo es; aun cuando esas lascas después puedan servir para hacer punzones con los cuales coser el cuero. Es decir: la piedra con la que se inició todo el proceso, aunque seguramente fue escogida por su forma conveniente, funcional, no es un objeto diseñado: ella no es resultado de un proceso de diseño; como tampoco lo son, por otro lado, las lascas que se desprenden de ella durante el tallado. Aunque éstas, luego y accidentalmente, también se muestren convenientes para la manufactura de otras herramientas.

El martillar del tallador sobre la piedra es un proceso de diseño en lo atinente al hacha; pero no lo es en lo atinente a las lascas: con relación a éstas ese martillar es semejante a la acción del agua sobre los cantos rodados. Cuando la obtención, o el incremento, de un desempeño funcional se encuentra sólo del lado de los efectos de un proceso, éste no es un proceso de diseño; para que lo sea es necesario que, de alguna forma, ese incremento esté del lado de las causas que ordenan y pautan ese proceso. Y esto lo vemos en lo que suele ocurrir con nuestros zapatos después de un año de andarlos. El uso, con el tiempo, produce modificaciones en ellos que, en general, los hacen más confortables; pero nadie dirá que esos cambios son mejoras de diseño: esos cambios son, simplemente, deformaciones producidas por un proceso totalmente ajeno a esa eventual mejora funcional. El uso, aunque muchas veces mejora, y de un modo pronunciado, la funcionalidad de los objetos utilizados, no es un proceso de diseño: no hagamos de miseria virtud.

La selección natural, en cambio, sí es un proceso de diseño (cf. Dennett 1995, p.187 y ss; Caponi 2002, p.15 y ss): ella va modificando los caracteres de los diferentes linajes de seres vivos siguiendo, de una manera oportunista y puntillosa, la senda que le marcan, que le imponen, pequeñas, o no tan pequeñas, diferencias e incrementos del desempeño funcional de las distintas partes y pautas comportamentales de dichos seres. La selección natural registra y acentúa, por acumulación, dichas diferencias en el cumplimento de lo que aquí llamé funciones biológicas; y ella sólo actúa en virtud de dichas diferencias. Dennett (1995, p.185) ha dicho, por eso, que "el trabajo hecho por la selección natural es Investigación \& Desarrollo"; y Francisco Ayala (2004, p.52) usó la feliz fórmula "diseño sin diseñador" para referirse 
al resultado de ese proceso estricta y claramente pautado por el incremento de la efectividad con la que se cumplen diferentes funciones biológicas.

\section{Función, eficacia y diseño en Ecología}

El hecho de que en Ecología puedan existir términos, imputaciones y análisis funcionales, se comprende fácilmente a partir de la propia noción de función como papel causal: en principio, y como ya lo dije, todo proceso causal puede ser funcionalmente analizado (cf. El-Hani \& Nunes 2006, p.42; Gayon 2010, p.134); y cuanto más complejo es ese proceso, más relevantes son las imputaciones de papeles causales, o funciones, que hagamos en nuestro esfuerzo por explicar cómo es que él pudo efectivamente ocurrir. Aseverar que una determinada especie de insecto es polinizadora de tal o cual planta es lo mismo que decir que ese insecto tiene una función, un papel causal, en el proceso de fertilización de dicha planta; y afirmar que, para determinadas plantas, ese insecto es un polinizador más eficiente que otro, significa que su comportamiento y su morfología promueven dicha polinización con mayor seguridad y frecuencia.

Pero esto no quiere decir que la mayor eficiencia en el cumplimiento de dicha función polinizadora, deba ser considerada como efecto de un proceso de diseño: ella no surgió de un proceso que haya estado pautado por refuerzos sucesivos de su incremento progresivo. La morfología y el repertorio comportamental de esos insectos, es verdad, pueden considerarse, en su mayor parte si se quiere, como resultado de la selección natural: un proceso al cual ya caractericé como productor de diseño. Podemos suponer, en efecto, que fue la selección natural la que ajustó esa morfología y afinó ese repertorio comportamental, reforzando y acumulando modificaciones que permitían un mejor desempeño en el cumplimiento de las diferentes funciones biológicas que esos insectos deben cumplir para sobrevivir. Pero entre esas funciones no estaba, seguramente, la polinización, aunque tal vez sí el mejor aprovechamiento, de la planta en cuestión. Esa polinización, para decirlo de algún modo, era invisible para las presiones selectivas que actuaron sobre ese linaje de insectos. La morfología y el repertorio de comportamientos de éstos, que por un efecto colateral los tornaron polinizadores más eficientes que otros, resultaron de presiones selectivas ajenas a las necesidades de las plantas que de ellos se beneficiaron.

Podemos imaginar, por ejemplo, que, en gran medida, la eficiencia polinizadora de estos insectos obedece a la singular conformación de sus extremidades. Pero sería imposible imaginar una presión selectiva que haya premiado esa conformación en virtud del incremento en la eficacia polinizadora por ella generado. Esa conformación podría ser, por ejemplo, una característica mimética que hace que ese insecto, de hecho inofensivo, sea confundido con otro venenoso por los pájaros insectívoros

Principia 14(3): 349-373 (2010). 
que también andan por ahí. Pero eso no es impedimento para que la conformación de sus patas transforme a ese insecto en un excelente transportador del polen de la planta de cuyo néctar él se alimenta. Por eso, aunque sea cierto que la población de esos insectos se vea beneficiada y sostenida por la abundancia en el ambiente de esa planta de cuyo néctar ellos se alimentan, y a cuya proliferación contribuyen, es imposible, pero también innecesario, imaginar cómo la selección natural sería capaz de captar ese beneficio que, de hecho, su eficacia como agentes polinizadores les trae a esos mismos insectos.

Es cierto también que la propia morfología de la planta pudo haber evolucionado para facilitar su fertilización por dichos insectos; y eso puede ser en parte responsable del hecho de que estos últimos sean más eficientes que otros en el cumplimiento de su función polinizadora. Las plantas en cuestión, diríamos, están más adaptadas a ellos que a otros insectos que eventualmente también las visitan buscando néctar; y por eso estos últimos no funcionan igual de bien como polinizadores. Pero sería un error pensar que las presiones selectivas que actuaron sobre esas plantas hayan operado en virtud de la ventaja que la conformación de sus flores les traía a sus polinizadores más habituales. Ellas también eran ciegas para los beneficios que esa evolución les generaba a esos insectos.

Éstos, claro, se vieron beneficiados por dicha evolución; y al beneficiarse también beneficiaron a las plantas que los alimentaban. Pero eso no significa que haya existido una presión selectiva específica para esa co-evolución. Lo que hubo fueron dos presiones selectivas distintas e independientes: una que actuó sobre el linaje de plantas, delineando la conformación de las flores de manera tal que fuesen más atractivas y accesibles para sus polinizadores; y otra que premio la conformación de esos polinizadores haciéndolos semejantes a insectos venenosos. Por eso, aunque su morfología los acabó transformando en polinizadores muy eficientes, no por eso decimos que la misma sea una adaptación a la polinización. No decimos, en suma, que esos insectos están diseñados en virtud de un incremento de su eficacia como polinizadores; como sí podríamos decir que están diseñados en virtud de la protección mimética que su morfología les otorga.

Es digno de ser observado, por otra parte, que consideraciones semejantes a éstas también podrían ser hechas si, en lugar de pensar que la morfología de esos insectos obedece a una función mimética, pensamos que ella fue seleccionada precisamente por el hecho de facilitar la explotación que dichos insectos hacen de las flores que los alimentan. En este caso, se podría pensar, la misma morfología que permite esa mejor explotación es la que también hace que esos insectos sean tan buenos polinizadores. Con todo, aun así, la presión selectiva que ahí habría actuado sobre los insectos tendría que ver con el éxito reproductivo de éstos y no con el éxito reproductivo de las plantas polinizadas. Otra vez, si esa morfología acabó haciendo que esos insectos fuesen polinizadores altamente eficientes, eso fue el efecto colateral 
de un proceso de selección pautado por una presión selectiva que nada tenía que ver con los beneficios que de ahí resultaban para las plantas. Y aquí sería oportuno recordar la, hoy, ya clásica distinción entre selección por [selection for] y selección de [selection of] propuesta por Elliott Sober (1984, p.100):

Selección de [selection of] refiere a los efectos del proceso de selección, mientras que selección por [selection for] describe sus causas. Decir que hay selección por una propiedad dada significa que tener esa propiedad causa éxito en términos de supervivencia y reproducción. Pero decir que un determinado tipo de objeto fue seleccionado es simplemente decir que el resultado del proceso de selección fue un incremento de la representación de ese tipo de objeto.

En el ejemplo hipotético que nos ocupa hubo, del lado de los insectos, selección por mimetismo o por [en favor de] una mayor eficacia en el comportamiento alimentar; y esas presiones selectivas condujeron, una u otra, a una selección de polinizadores más eficientes. Pero la historia inversa no hubiese sido posible: nunca podría haber existido una selección por polinizadores más eficientes que fuese capaz de conducir a una selección de caracteres miméticos o de comportamientos alimentares más eficaces. La "selección por", como dice Sober (1984, p.100), "es el concepto causal por excelencia"; la selección de pertenece, en cambio, al orden de los efectos. Y esa oposición también puede verse, aunque de una forma menos nítida, en el caso de las plantas. Sobre éstas actuó una selección por [en favor de] una morfología que hacía más fácil su propia polinización; y eso condujo a una selección de variantes que facilitaban su explotación por parte de los insectos en cuestión. La presión selectiva que actuaba sobre las plantas sólo podía premiar el mejor cumplimiento de esa función fertilizadora; ella jamás podría premiar el bienestar de los insectos. Aunque esta último haya sido un efecto directo de aquélla; y aunque ese bienestar haya redundado en un beneficio para las propias plantas.

Pero lo que vale para la eficiencia polinizadora de esos insectos también puede valer para las consideraciones que suelen hacerse sobre la eficiencia de los diferentes niveles de una cadena trófica y sobre los diferentes componentes de un mismo nivel de dicha cadena. ${ }^{6}$ Se puede hablar, por ejemplo, de ecosistemas cuyos organismos descomponedores son más eficientes que los de otro ecosistema, por el hecho de permitir que el ciclo producción-consumo-descomposición se cumpla con mayor rapidez y dejando un residuo menor de sustancias orgánicas no descompuestas. O se puede decir que hay especies cuya presencia o ausencia aumenta, o disminuye, la eficiencia de consumo ${ }^{7}$ de una cadena alimentar; y así hablaremos de especies, o conjunto de especies, que son asimiladores más eficientes porque, la diferencia entre la energía consumida por ellas y la energía que ellas dejan disponible para ser usufructuada por el nivel subsiguiente de la cadena trófica, es menor a la que se da en el caso de otras especies.

Principia 14(3): 349-373 (2010). 
Con todo, y aunque eventualmente la eficiencia de un ecosistema, o de un eslabón cualquiera de la cadena trófica, pueda verse incrementada, incluso por la propia incidencia de la selección natural, tampoco aquí se podrá hablar de sistemas diseñados. La selección natural puede tender, en efecto, a que las diferentes poblaciones de una comunidad o ecosistema se hagan más eficientes; y quizá ella casi siempre lo haga: individuos que puedan producir y sustentar una mayor descendencia, utilizando una menor cantidad de los recursos para ellos disponibles, tenderán a suplantar a aquellos que no puedan hacerlo; y así, dentro de los constreñimientos a los que la posible evolución de cada linaje de seres vivos está sujeta (Futuyma 2010), habrá siempre una tendencia al incremento de la eficiencia de consumo de cada población. Pero, aunque esto sea así, seria incorrecto afirmar que allí opere una presión selectiva que actúe favoreciendo un incremento de la eficiencia de consumo del ecosistema como un todo.

La selección natural, como ocurría en el caso de la eficiencia de los polinizadores, es ciega para ese incremento. Lo que ella impulsa es un cambio en una población, premiando con mayor éxito reproductivo a individuos con ciertas características; y es sólo como efecto colateral de ese cambio poblacional que la eficiencia global del ecosistema se ve incrementada. La selección natural no tiene cómo registrar este último incremento: ella sólo registra diferencias de aptitud entre los individuos, y quizá entre diferentes grupos (Wilson 2004), que compiten entre sí dentro de una misma población. Y son esas diferencias que ella premia o castiga. Por eso, aunque no podamos negar que la selección natural modifica los sistemas ecológicos al modificar las poblaciones que los integran, mal podemos decir que ella los diseñe; en este sentido "los sistemas ecológicos como tales no evolucionan" (May 1979, p.103): ellos, simplemente, cambian. Pensar lo contrario sería un error análogo al de pensar que la disminución del precio del trigo fue el resultado que buscaron todos aquellos productores que se esforzaron por conseguir una mejor cosecha.

Por otro lado, y como Darwin (1859, p.112) ya lo había previsto al formular su principio de divergencia (cf. Mikkelson 2007, p.381), la selección natural también tenderá siempre a disminuir cualquier residuo de energía producido por un eslabón de la cadena trófica que no sea utilizado por el eslabón subsiguiente. Si las bacterias de un ecosistema cualquiera no consiguen descomponer alguna parte de los residuos de materia orgánica ahí generados, siempre habrá un premio importante para cualquier variante de alguno de esos linajes de bacterias que consiga hacerlo. Y eso, claro, también tendrá como consecuencia un incremento en la eficiencia global de todo el ecosistema. Pero ahí, lo premiado, lo efectivamente seleccionado, lo que es blanco de la selección por, es la capacidad o propensión a usufructuar recursos disponibles menos escasos; y es esa presión selectiva que, actuando sobre la población de bacterias, produce, como efecto colateral, un incremento en la eficiencia global del ecosistema. La selección por la capacidad de usufructuar recursos disponibles menos 
escasos, que modela un sublinaje de bacterias, redunda en la selección de características que contribuyen al incremento de la eficiencia del ecosistema.

Así, aunque la selección natural pueda modificar las poblaciones de una forma tal que, eventualmente, incremente la eficiencia de éstas en el cumplimiento de esas funciones ecológicas tales como polinización o descomposición, no por eso diremos que esas poblaciones están naturalmente diseñadas para ese desempeño funcional; y no lo diremos porque la selección natural es definitivamente indiferente para con el perfeccionamiento de ese desempeño. Ella sólo registra [y sólo obedece a] las modificaciones que optimizan la contribución funcional de ciertas estructuras en el cumplimiento de los ciclos vitales de vivientes individuales, o, como ya dije, de grupos que puedan ser competidores de otros grupos dentro de una población. La selección natural sólo actúa en favor de esas modificaciones. Así, no obstante el hecho de que quizá se pueda demostrar que, a largo plazo o por lo general, la selección natural contribuya al incremento de la eficiencia global de los ecosistemas; no por eso diremos que esos ecosistemas están diseñados por la selección natural.

Esa optimización en el desempeño funcional del ecosistema sólo fue un efecto colateral, o accidental, de un proceso que no podía registrarlo y del cual, entonces, mal podríamos decir que se ordenó en virtud de su refuerzo o acentuación; como sí ocurre con la selección natural cuando ella actúa sobre caracteres como una coloración protectora. La selección natural puede registrar y acentuar mejoras el desempeño funcional de los seres vivos; independientemente de que eso conlleve o no una mejora funcional del sistema ecológico en el que esos seres vivos medran. Y que esto último ocurra, que la selección natural acabe teniendo muchas veces, o siempre, ese efecto accidentalmente optimizador sobre los sistemas y procesos ecológicos, es una de las condiciones que permiten la existencia de la vida. Sin ella, probablemente, los ecosistemas no sólo no tendrían la eficiencia que efectivamente tienen, sino que además es muy posible que ellos tampoco pudiesen existir.

Por todo esto, aunque no dudo de que los sistemas y procesos ecológicos puedan ser funcionalmente analizados, y aunque tampoco dudo de que su eficiencia se pueda ver de hecho muchas veces incrementada por un efecto colateral, indirecto, de la selección natural, ${ }^{8}$ creo que eso no puede llevarnos nunca a pensar que dichos sistemas y procesos sean procesos y sistemas diseñados, como sí lo son aquellos que son el blanco propio y directo de la selección natural. Hay presiones selectivas actuando dentro de comunidades y ecosistemas; es decir: hay selección natural actuando sobre los sublinajes que perviven al interior de esos sistemas. $\mathrm{Y}$ eso incide sobre la propia dinámica y estructura de esas comunidades y ecosistemas. Pero no hay selección natural actuando sobre comunidades y ecosistemas: no hay competencia y reproducción diferencial de sistemas y procesos ecológicos; y por eso no podemos considerarlos como objetos diseñados.

Creo importante decir, además, que los sistemas ecológicos son pasibles de ser

Principia 14(3): 349-373 (2010). 
analizados en virtud de esa operación cognitiva que, de un modo que entiendo equivocado, Arno Wouters (2007) llamó explicaciones de diseño. Cabe, en efecto, que nos preguntemos por qué un ecosistema tiene que tener organismos descomponedores; y nuestra respuesta será que esos organismos son una condición de existencia para tales sistemas, porque, sin ellos, esos sistemas quedarían rápidamente abarrotados de cadáveres incorruptos y, así, el ciclo energético se vería interrumpido. Los organismos descomponedores, podríamos decir, son una necesidad organizacional de todo ecosistema. Pero no significa que ellos estén ahí para suplir esa necesidad, ni que ellos hayan evolucionado para mejor satisfacerla; y eso muestra que esos análisis que Wouters llama explicaciones de diseño pueden ser aplicados a sistemas que no caracterizaríamos como diseñados. Por eso es que no creo que la expresión propuesta por Wonters sea adecuada para denotar esos análisis relativos a prerrequisitos organizacionales.

\section{Orden y desorden}

Sólo la organización vence al tiempo. General Juan Domingo Perón

Hasta aquí, sin embargo, sólo cumplí con un parte de mi cometido. Hasta aquí sólo mostré la legitimidad del discurso funcional en Ecología y su completa desvinculación de cualquier idea que nos lleve a pensar los sistemas ecológicos como objetos diseñados. Pero, como lo apunte desde el inicio, lo más intrigante de la Ecología no está en el hecho de que allí ocurran, o abunden, los análisis funcionales; sino en el hecho de que casi todo el discurso de esa disciplina y, sobre todo, sus conceptos fundamentales sean, como también ocurre en el caso de la Fisiología (Gayon 2010, p.125), de naturaleza eminentemente funcional. Así, aunque nos haya quedado claro que los análisis funcionales de la Ecología no presuponen que los procesos y sistemas ecológicos sean resultantes de procesos de diseño, puede quedar todavía la sospecha de que la ubicuidad del discurso funcional en ese domino disciplinar sea el síntoma de la vergonzante pervivencia de un insostenible pensamiento organicista.

Creo, sin embargo, que la razón de ser de esa afinidad, o de ese paralelismo, entre los discursos de la Fisiología y de la Ecología no reside en el hecho de que esta última disciplina permanezca sujeta a un imaginario organicista. Lo que motiva esa afinidad entre ambas disciplinas es, según entiendo, algo mucho más profundo: algo que tiene que ver, como dije en la Presentación, con el hecho de que una y otra trabajen sobre la presunción de sendos ideales de orden natural (Toulmin 1961, p.44 y ss), vinculados éstos, con la oposición orden improbable-desorden probable. Ambas disciplinas se dan a sí mismas la tarea de explicar la persistencia y la recurrencia de fenómenos y estados de cosas considerados, desde el inicio, como poco probables; y su discurso se torna eminentemente funcional porque lo que primeramente importa

Principia 14(3): 349-373 (2010). 
al conceptualizar un proceso o sistema cualquiera, es entender y subrayar su función, su papel causal, en la consecución y en la preservación de esos estados de cosas que, justamente por el hecho de ser considerados improbables, son también considerados como necesitados de explicación.

En Predicción y Entendimiento, Toulmin (1961, p.57) presenta los ideales de orden natural como principios que, para una teoría determinada o para un dominio específico de indagación, definen el horizonte de constancia o de regularidad sobre el que habrán de perfilarse, como desvíos de él, los hechos que dicha teoría, o dicho dominio de indagación, asume como necesitados y pasibles de explicación. Un hecho, podríamos decir, es lo de algún modo inesperado que irrumpe sobre un horizonte de permanencia que la teoría, o el dominio de investigación en análisis, al presuponer un cierto ideal de orden natural, acepta como algo obvio y auto-explicado; y decir esto es lo mismo que afirmar que un hecho es aquello que, dado un ideal de orden natural, aparece como necesitado de explicación.

Así, y como ejemplo paradigmático de esos ideales Toulmin (1961, p.56) nos propone al Principio de Inercia: todo cuerpo continúa en estado de reposo, o de movimiento rectilíneo y uniforme, a menos que sea compelido a cambiar dicho estado de movimiento por aplicación de una fuerza. Esta primera ley de Newton, nos dice Toulmin (1961, p.62-3), indica que, para la mecánica newtoniana, la permanencia de un cuerpo en cualquiera de esos dos estados es lo esperable, lo normal, lo natural: lo que va de suyo y, por eso, no requiere explicación. Lo que debe ser explicado, lo que debe ser objeto de interrogación, es, por lo tanto, la salida del reposo o la salida del movimiento rectilíneo uniforme; y toda la mecánica newtoniana nos ofrece el modo de responder esas cuestiones, permitiéndonos explicar y calcular los desvíos de ese estado u orden ideal, apelando a leyes adicionales como, por ejemplo, la Ley de Gravitación.

Pero, al igual que otros aspectos de la gramática científica, los ideales de orden natural son regionales: diferentes teorías científicas o, más en general, diferentes dominios disciplinares, pueden obedecer a ideales diferentes; ${ }^{9}$ y es sobre el horizonte de esos diferentes ideales de orden natural que se perfilan y cobran sentido los objetivos explicativos de cada teoría o de cada dominio específico de investigación. Lo que en cada caso se considera como obvio, como natural, de por sí explicable, es distinto; y eso hace que también sea diferente lo que, en cada caso, habrá de considerarse como desvío, a ser explicado, de ese estado natural. Ideales de orden natural diferentes, al establecer las más diversas discriminaciones entre lo que necesita y no necesita explicación, generan y nos comprometen con diferentes emprendimientos explicativos; cada uno con sus perplejidades y sus interrogantes fundamentales.

Así, desde Xavier Bichat (1994[1801], p.57) y Claude Bernard (1878, p.66) en adelante, el problema central de la Fisiología ha sido el de mostrar cómo el orden orgánico, la vida, se genera y se preserva, no obstante su relativa improbabilidad 
física (cf. Schrödinger 1984[1944], p.110-1). La pregunta básica de la Fisiología parece ser siempre ¿Por qué la vida y no más bien la muerte? Esta última, la muerte, define para la Fisiología el estado natural y más probable de cosas: un estado que, en primera instancia, no es necesario explicar; porque lo que ocurre en él es algo de lo cual la Física y la Química ya nos dan una explicación. Lo que es necesario explicar es el hecho de que, no obstante esa mayor probabilidad de la muerte, el orden de la vida se preserve. Ésta aparece así como el desvío improbable, y problemático, de un estado de cosas que se considera ya antes explicado por la Física y por la Química; y es en contraste con los exigentes requisitos organizacionales que el orden de la vida debe satisfacer para sostenerse, que este último estado de cosas, el de lo no-vivo, es percibido como un estado de desorden.

El problema recurrente de la Ecología, mientras tanto, es el de explicar la ocurrencia de procesos, $\mathrm{u}$ ordenamientos, que pueden ir del mero ciclo vital de un organismo en la naturaleza hasta un ciclo trófico cuya recurrencia permite la existencia de ciertas formas de vidas. El primer tipo de proceso es aquel estudiado por la Autoecología; y su parcial superposición con el tipo de proceso estudiado por la Fisiología ya fue apuntado en la nota 2 de este trabajo. El segundo tipo de proceso, mientras tanto, es aquel estudiado por la Ecología de los ecosistemas; pero entre esos dos extremos existe toda una gradación de fenómenos, procesos y estados de cosas, de diferente complejidad, que el ecólogo también estudia intentando mostrar cómo es que ellos pueden ocurrir y eventualmente preservarse o repetirse. Tal el caso, por ejemplo, de la persistencia de una determinada comunidad integrada por poblaciones de distintas especies. Pero, en todos los casos, la presunción del ecólogo parece ser la misma: esos procesos, esos estados de cosas, esos ordenamientos, son relativamente improbables, son relativamente frágiles; ellos suponen una articulación, una sintonía afinada, de ciertos factores cuya condición de posibilidad y cuya ocurrencia es necesario explicar.

El problema central de la Ecología, dicho de otro modo, es el de mostrar cómo esos procesos y órdenes improbables se instauran y se sostienen, no obstante todas las contingencias que pueden tender a su más probable desarticulación. Los sistemas ecológicos, y los procesos que los posibilitan, son mecanismos intrincados y delicados que, a primera vista por lo menos, cualquier desajuste podría llegar a comprometer; y el ecólogo quiere saber cómo, no obstante eso, sus piezas y sus momentos se encajan, y se concatenan, de modo tal que, pese a esa relativa fragilidad, ellos puedan sustentarse, aunque sea durante lapsos muy cortos de tiempo. La sustentabilidad es, por eso, la gran cuestión de la Ecología; y atribuir funciones a los componentes o momentos de los sistemas o procesos ecológicos, es intentar mostrar cómo ellos contribuyen al sostenimiento de esos estados o procesos considerados improbables, problemáticos, y, por lo tanto, merecedores de explicación. La conceptualización funcional de entidades y procesos que tipifica a la Ecología, no 
es más, entonces, que la contratara de esa preocupación por la sustentabilidad: ahí los fenómenos y las entidades en estudio son considerados, básica y primariamente, en virtud de su contribución causal en esos órdenes o procesos cuya sustentabilidad queremos explicar.

La indagación fisiológica y la ecológica operan, en suma, sobre la presunción de estados de desorden considerados como más probables que los ordenamientos o procesos cuya inesperada preservación u ocurrencia, ellas quieren explicar y, por eso, los privilegian en sus análisis. Esos estados de orden, en el caso de la Fisiología, pueden ser la propia autopoiesis o los subprocesos que hacen a ésta posible (cf. Maturana \& Varela 1995, p.69). En la Ecología, mientras tanto, esos estados de orden pueden ser la persistencia de ecosistema, de una comunidad, de una población (Walter 2008); y, si nos remitimos a la Autoecología, también incluiremos ahí a la preservación de un viviente individual. Pero también podemos pensar esos órdenes que le interesan al ecólogo en virtud de los procesos que los hacen posibles; tal el caso de la manutención de un ciclo energético, de una cadena trófica o la resiliencia de las complejas relaciones biológicas que aseguran la polinización de determinadas plantas o que facilitan la dispersión de sus semillas. Existe, sin embargo, y no lo estoy pasando por alto, una diferencia importante en el modo en el que puede hablarse de referencias a estados privilegiados en Fisiología y en Ecología.

En el caso de la Fisiología, lo sabemos porque la investigación empírica así nos lo ha enseñado, esos estados privilegiados que queremos explicar son sostenidos, en gran parte, por mecanismos de regulación, propios de los seres vivos, que responden específicamente a las perturbaciones sufridas por la autopoiesis, y que, además, suponemos que han sido diseñados por la selección natural para mejor cumplir con esa función. ${ }^{10}$ En el caso de la Ecología, en cambio, es materia discutible que tales mecanismos existan. Eugene Odum (1988, p.29), es cierto, consideró a los ecosistemas como sistemas cibernéticos autorregulados por mecanismos de retroalimentación (cf. McIntosh 1985, pp.231-2; Kwa 1986, p.168-9); y James Lovelock (1985, p.65; 1993, p.75) extendió ese modo de pensar a nivel planetario (Bowler 1998, p.399; El-Hani \& Nunes 2006, p.16): Gaia es un gran ecosistema (cf. Peacock 2008, p.359). ${ }^{11}$ Pero, hablar de sistemas autorregulados exige apuntar mecanismos específicos de autorregulación: exige apuntar mecanismos cuyas operaciones, además de equilibrar y reequilibrar al sistema en cuestión, también sean reacciones, específicas y proporcionales, a las perturbaciones que dicho sistema pueda eventualmente padecer; y que los ecosistemas contengan tales mecanismos es una cuestión polémica (cf. Brewer 1994, p.372; Williams 1997, p.405; Kirchner 2007, p.314).

Los incendios forestales, según se dice, tienen un efecto regulador importante, una función, en la preservación de algunos ecosistemas (cf. Deléage 1991, p.238). Pero de ahí no se deduce que tales incendios sean una reacción específica y proporcional a los estados de cosas, o a los procesos, contrarios a la eficacia global del 
ecosistema, que ellos permiten revertir o limitar. Esos incendios no son una reacción del bosque ante su propia decrepitud: ellos son sólo eventos cuya ocurrencia, frecuente, pero en general desencadenada por factores externos al propio ecosistema, acaba contribuyendo al reciclaje de las materias nutritivas que el bosque necesita para renovarse. El rayo que cae sobre un árbol seco, o la hoguera que unos turistas dejan mal apagada, no son reacciones del bosque a la acumulación de madera muerta no reciclada. Aunque esa misma acumulación sea una condición que aumenta el riesgo del incendio, tornando más probable que la caída de un rayo lo desencadene, nada hay en el bosque decrépito que llame a los rayos o a los turistas. Pero, sea como sea, lo cierto es que la cuestión de si existen o no mecanismos ecológicos de autorregulación, es de de carácter empírico; y por eso ella escapa al análisis filosófico. Éste puede contribuir a la delimitación del concepto de mecanismo de autorregulación: nada puede decir, sin embargo, sobre su existencia.

Creo, de todos modos, que aunque se llegue a una delimitación precisa de ese concepto y después se arribe a la conclusión de que los mismos sistemas ecológicos no cuentan con ellos, cosa que me parece totalmente plausible, eso no invalidaría la idea que aquí estoy intentando delinear. Que existan o no existan mecanismos ecológicos de autorregulación es, como dije, una cuestión empírica que nada tiene que ver con el hecho de que la Ecología obedezca, toda ella, al objetivo de explicar cómo es que ciertos procesos o estados, cuya ocurrencia está lejos de derivarse inmediatamente de la pura legalidad física o química, y que además suponen la compleja conjugación de múltiples y diversos factores bióticos y abióticos, pueden ocurrir de forma tal que aseguren, o por lo menos le den sustento, por algún tiempo, a determinadas formas de vida o a determinadas asociaciones entre esas formas de vida. Y lo que digo sobre la posible existencia o inexistencia de mecanismos autorreguladores en los ecosistemas, también vale para la cuestión, hoy discutida en Ecología de las Poblaciones y de las Comunidades, de si existe o no algo así como un punto de equilibrio en torno del cual la densidad de las poblaciones habría de fluctuar (cf. Cooper 2003, p.75; Walter 2008, p.420).

Ésa también es una cuestión empírica (Colyvan 2008, p.312) sobre la que aquí no cabe entrar; y que además tampoco es relevante para discutir lo que aquí se está sosteniendo. Estén o no en equilibrio las poblaciones que componen los sistemas ecológicos, éstos, junto con los subsistemas que los integran y los procesos que los sostienen, están, por mucho o por poco tiempo, efectivamente ahí; y el ecólogo, que los presupone improbables, querrá saber cómo es que eso resulta posible. Algunos organismos completan sus ciclos vitales; y, mal o bien, el ciclo trófico continúa: he ahí las dos puntas de una serie de fenómenos cuya explicación la Ecología asume y privilegia como constituyendo su desafío cognitivo fundamental; incluso para buscar en esa explicación las claves para entender cómo y por qué esos fenómenos pueden llegar a no ocurrir o a verse comprometidos. 
Sabiendo cuáles son las funciones que deban ser cumplidas para que esos procesos ocurran, y sabiendo cómo y por cuáles entidades ellas son cumplidas, el ecólogo podrá explicar porque dichos procesos a veces no ocurren o no se cumplen de la manera esperada. Conociendo cual era el polinizador más eficiente de determinadas plantas, podremos explicar una disminución en la población de éstas, apuntando la desaparición parcial o total de ese polinizador y su sustitución por otro menos eficiente. Y en esto, claro, la analogía entre la Ecología y la Fisiología vuelve a hacerse patente: sabiendo cómo es que se instauran y se preservan esos órdenes improbables de cosas que una y otra quieren explicar, ambas disciplinas también pueden dar cuenta de cómo es que, una vez instaurados, dichos órdenes pueden eventualmente desarticularse o desmoronarse.

Creo, de todos modos, que lo que aquí ha sido dicho sobre los objetivos cognitivos de la Ecología, y sobre la razón de ser de su conceptualización funcional de los fenómenos por ella estudiados, sirve también para entender lo que Gregory Cooper (2003, p.75) ha apuntado sobre la persistencia, no siempre reflexiva, de la idea de equilibrio natural en las teorizaciones ecológicas. Porque, aun sin estar lógicamente comprometida con esa idea, la noción de sustentabilidad puede, de algún modo, superponerse y confundirse con la de equilibrio. Sustentabilidad parece remitir a estabilidad; y estabilidad parece remitir a equilibrio. Y aunque ciertamente se trate de una asociación injustificada, la misma puede ayudarnos entender el hecho de que la explicación de la sustentabilidad haya sido muchas veces confundida con la explicación de supuestos estados de equilibrio. El equilibrio de la naturaleza sería la manifestación distorsionada, ideológica, de esa sustentabilidad, intrigante por exigencia de un ideal de orden natural, de los procesos ecológicos. Esa sustentabilidad que, también por exigencia de ese mismo ideal de orden natural, la Ecología no puede renunciar a explicar, porque hacerlo sería lo mismo que clausurar toda indagación ecológica. La mera Física y la mera Química de la biosfera nunca nos darían una Ecología.

Pero, algo semejante a lo que digo sobre la idea de equilibrio, también puede ser dicho sobre el origen y la pervivencia, más o menos temperada, de las imágenes organicistas en el discurso ecológico. Ahí está la teoría de Gaia para ilustrar lo que estoy diciendo; pero ahí están también las tan innegables como legítimas analogías entre Fisiología y Ecología que sirven para explicar la recurrencia de esas imágenes. Limitadamente, esas analogías son, en efecto, tan legítimas como inevitables; y las imágenes organicistas también pueden ser consideradas como la manifestación distorsionada, ideológica, de dichas analogías. Esas imágenes denuncian, y hasta confirman, la sujeción de la Ecología a un ideal de orden natural que no deja de tener alguna semejanza, alguna afinidad, con aquél que ordena y pauta a la investigación fisiológica.

La retórica organicista, o cuasi-organicista de Clements, de Odum y de Lovelock puede resultarnos inaceptable; pero no hay duda de que ella es entendible. Ella 
puede ser inadecuada para describir a las comunidades ecológicas, a los ecosistemas y a la Tierra; pero, aunque vagamente, ella nos insinúa algo que es constitutivo de la indagación ecológica. Diciéndonos algo que es falso empíricamente, las metáforas organicistas de la Ecología apuntan algo que es válido epistemológicamente. Creo que vale, y valió, la pena tomarlas un poco en serio.

\section{Referencias}

Acot, P. 1988: Histoire de la Ecologie. Paris: PUF.

Allen C. \& Bekoff, M. 1998. Biological function, adaptation, and natural design. In Allen, C.; Bekoff, M.; Lauder, G. (eds.) Nature's purpose: analysis of function and design in Biology. Cambridge: MIT Press, pp.571-88.

Ayala, F. 2004. In William Paley shadow: Darwin explanation of design. Ludus Vitalis 12(21): 53-66.

Begon, M.; Townsend, C.; Harper, J. 2006. Ecology: from individuals to ecosystems. Malden: Blackwell.

Bernard, C. 1878. Leçons sur les phénomènes de la vie communs aux animaux et aux végétaux. Paris: Baillière.

Bichat, X. 1994[1801]: Recherches physiologiques sur la vie et la mort (première partie). In Bichat, X. 1994. Recherches physiologiques sur la vie et la mort et autres textes. Paris: Flammarion, pp.55-209.

Borges, J. [1921]1997. La metáfora. In Borges, J. Textos recobrados: 1919-1929. Barcelona: Emecé, p.114-20

Bowler, P. 1998. Historia Fontana de las Ciencias Ambientales. México: Fondo de Cultura Económica.

Brewer, R. 1994. The science of ecology. New York: Saunders.

Caponi, G. 2002. La sabiduría de las especies: las poblaciones biológicas como sistemas cognitivos. Ludus Vitalis 18: 9-38.

- 2004. La navaja de Darwin. Ludus Vitalis 22: 9-38.

- 2005: O Principio de Hardy-Weinberg como ideal de ordem natural da Biologia Evolutiva. In Regner, A. \& Rohden, L. (eds.) A filosofia e a ciência redesenham horizontes. São Leopoldo: UNISINOS, pp.225-35.

—. 2007a: Física del organismo vs Hermenéutica del viviente. História, Ciência, Saúde 14(2): 443-61.

- 2007b. El retorno de la ontogenia: un conflicto de ideales de orden natural en la biología evolucionaria actual. Scientiae Studia 5(1): 9-34.

- 2008. El segundo pilar: la Biología Evolucionaria Desenvolvimiental y el surgimiento de una teoría complementaria a la Teoría de la Selección Natural. Ludus Vitalis 29: 2-32.

- 2010a. Análisis funcionales y explicaciones seleccionales en Biología: una crítica de la concepción etiológica del concepto de función. Ideas y Valores 58(143): 51-72.

—. 2010b. Función, adaptación y diseño en Biología. Signos Filosóficos 12(24): 71-101.

_. 2010c. La Biología Evolucionaria Desenvolvimiental según su ideal de orden natural.

Princípios 17(27): 5-29.

Principia 14(3): 349-373 (2010). 
Colyvan, M. 2008. Population ecology. In Sarkar, S. \& Plutynski, A. (eds.) A companion to the Philosophy of Biology. Malden: Blackwell, pp.301-20.

Cooper, G. 2003: The science of the struggle for existence: on the foundations of ecology. Cambridge: Cambridge University Press.

Craig, L. \& Pechmann, J. [1988]2000. Evolution: the missing ingredient in Systems Ecology. In Keller, D. \& Golley, B. (eds.) The Philosophy of Ecology. London: The University of Georgia Press, pp.304-19.

Cummins, R. 1975. Functional analysis. The Journal of Philosophy 20: 741-65.

Darwin, C. 1859. On the origin of species. London: Murray.

Deléage, J. 1991. Une histoire de l'écologie. Paris: La Découverte.

Dennett, D. 1995. Darwin's dangerous idea. London: Penguin.

Donlan, J. 2010. O retorno dos grandes animais da América. Scientific American Brasil, edição especial: Paleontologia, pp.42-49.

Donlan, J.; Berger, J.; Bock, C.; Bock, J.; Burney, D.; Estes, J.; Foreman, D.; Martin, P.; Roemer, G.; Smith, F; Soulé, M.; Greene, H. 2006. Pleistocene rewilding: an optimist agenda for twenty-first century conservation. American Naturalist 168: 660-81.

Drouin, J. 1993: L'Écologie et son histoire. Paris: Flammarion.

El-Hani, C. \& Almeida, A. 2006. Atribuição de função à biodiversidade segundo a visão do papel causal: uma analise epistemológica do discurso ecológico das duas últimas décadas. In Prestes, M.; Marins, L.; Stefano, W. (eds.): Filosofia e História da Biologia, Vol. I. São Paulo: MackPesquisa, pp.21-39.

El-Hani, C. \& Nunes, N. 2006. Gaia, teleologia e função. Episteme 11: 15-48.

- 2009. Functional languaje in evolutionary biology, ecology and earth sciences. In Caponi, G. \& Mortari, C. (eds.), Charles Darwin e seu impacto na filosofia e na ciência (livro de resumos do VI Simpósio Internacional Principia). Florianópolis: NEL/UFSC, pp.70-71.

Futuyma, D. 2010. Evolutionary constraint and ecological consequences. Evolution 64(7): $1865-84$.

Gayon, J. 2010. Raisonnent fonctionnel et niveaux d'organisation en Biologie. In Gayon, J. \& Ricqlès, A. (eds.) Les fonctions: des organismes aux artefacts. Paris: PUF, pp.125-38.

Goldstein, K. 1951. La structure de l'organisme. Paris: Gallimard.

Keller, E. 2010. It is possible to reduce biological explanation to explanation in Chemistry and/or Physics. In Ayala, F. \& Arp, R. (eds.) Contemporary debates in Philosophy of Biology. London, Wiley-Blakwell, pp.19-31.

Kirchner, J. 2007. The Gaia hypothesis: fact, theory, and wishful thinking. In Ruse, M. (ed.) Philosophy of Biology. Amherst: Prometheus Books, pp.309-28.

Kwa, C. 1986. Representation of nature in cybernetic and evolutionary ecology. In Weingartner, P. \& Dorn, G. (eds.) Foundations of Biology. Viena: Hölder-Pichler-tempsky, pp.16790.

Lincoln, R.; Boxshall, G.; Clarck, P. 2009. Diccionario de Ecología, Evolución y Taxonomía. México: Fondo de Cultura Económica.

Lovelock, J. 1985. Gaia: una nueva visión de la vida sobre la tierra. Madrid: Orbis.

-1993. Las edades de Gaia. Barcelona: Tusquets.

Maturana, H. \& Varela, F. 1995: De máquinas y seres vivos. Santiago de Chile: Editorial Universitaria.

Principia 14(3): 349-373 (2010). 
May, R. 1979. La evolución de los sistemas ecológicos. In Scientific American (ed.): Evolución. Barcelona: Labor, pp.101-14.

McIntosh, R. The Background of Ecology. Cambridge: Cambridge University Press.

Mikkelson, G. 2007. Ecology. In Hull, D. \& Ruse, M. (eds.) The Cambridge Companion to the Philosophy of Biology. Cambridge: Cambridge University Press, pp.372-87.

Odum, E. 1963. Ecology. New York: Holt, Rinehart and Winston

- 1988. Ecologia. Rio de Janeiro: Guanabara.

Parrochia, D. 1994. Des réseaux trophiques aux écosystèmes. In Acot, P. (ed.): La maîtrise du milieu. Paris: Vrin, pp.79-100.

Peacock, K. 2008. Ecosystems. In Sarkar, S. \& Plutynski, A. (eds.) A companion to Philosophy of Biology. Malden: Blackwell, pp.351-67.

Ponce, M. 1987: La explicación teleológica. México: UNAM.

Ricklefs, R. 2003. A economia da natureza. Rio de Janeiro: Guanabara.

Rosenfeld, J. 2002. Functional redundancy in ecology and conservation. OIKOS 98(1): 15662.

Schrödinger, E. 1984[1944]. ¿Qué es la vida? Barcelona: Tusquets.

Sergio, F.; Caro, T.; Brown, D.; Clucas, B.; Hunter, J.; Ketchum, J.; McHugh, K.; Hiraldo, F. 2008. Top predators as conservation tools: ecological rationale, assumptions, and efficacy. Annual Review of Ecology, Evolution and Systematics 39: 1-19.

Sober, E. 1984. The nature of selection. Chicago: The University of Chicago Press.

Tilman, D.; Knops, J.; Wedin, D.; Reich, P.; Ritchie, M.; Siemann, E. 1997. The influence of functional diversity and composition on ecosystem processes. Science 277: 1300-02.

Toulmin, S. 1961. Foresight and Understanding. Indianapolis, Indiana University Press.

Walter, G. 2008. Individuals populations and the balance of nature: the question of persistence in Ecology. Biology \& Philosophy 23: 417-38.

Williams, G. 1997. Gaia, nature worship, and biocentric fallacies. In Ridley, M. (ed.) Evolution. Oxford: Oxford University Press, pp.398-407.

Wilson, D. Los grupos humanos como unidades adaptativas: hacia un consenso teórico permanente. Ludus Vitalis 12(21): 91-108.

Wouters, A. 2007. Design explanation: determining the constraints on what can be alive. Erkenntnis 67: 65-80.

$$
\begin{array}{r}
\text { Gustavo CAPONI } \\
\text { Departamento de Filosofia } \\
\text { Universidade Federal de Santa Catarina } \\
\text { Florianópolis, SC } \\
\text { BRASIL } \\
\text { gustavoandrescaponi@gmail.com }
\end{array}
$$

Resumo. O objetivo cognitivo principal da Ecologia é a análise funcional dos processos e sistemas ecológicos. Isso não supõe, entretanto, que esses processos e sistemas estejam planejados; como sim o estão os seres vivos individuais. A Ecologia, de maneira semlhante à Fisiologia, está constitutivamente orientada pela presuposição de um estado privilegiado, a ser explicado, que é a persistência dos sistemas e processos por ela estudados; e suas análises funcionais respondem a essa presuposição. A Ecologia supõe um ideal de ordem natural, sob

Principia 14(3): 349-373 (2010). 
cuja consideração esse estado privilegiado é pensando como um estado de coisas improvável e, por isso, necessitado de explicação; e, no que se refere a este último ponto, a analogía entre a Ecologia e a Fisiologia também pode resultar esclarecedora.

Palavras-chave: Desenho, estado privilegiado, função, ideal de ordem natural, imputação funcional.

\section{Notas}

${ }^{1}$ Al respecto, ver: McIntosh 1985, p.75; Kwa 1986, p.169; Acot 1988, p.202; Deléage 1991, p.94-8 y p.119; Drouin 1993, p.138; Brewer 1994, p.372; Bowler 1998, p.391; El-Hani \& Nunes 2006, p.32-3.

2 Dejo de lado a la Autoecología porque ésta, en cierto sentido, es algo así como una Fisiología de extramuros: lo que a ella le preocupa es cómo una determinada estructura, comportamiento, o recurso, contribuye a la realización del ciclo vital de un ser vivo en un determinado ambiente. Allí, y como ocurre en el caso de la Fisiología tout court, la pertinencia y relevancia de los análisis funcionales no parece envolver mayores dificultades (cf. Caponi 2010a, p.62-3).

${ }^{3}$ En lo que atañe a la concepción sistémica de función, la referencia clásica, y casi obligada, es Cummins (1975). Con todo, debido a que mi interpretación esa concepción es un poco diferente a la de Cummins, y más comprometida con las tesis desarrolladas por Margarita Ponce (1987) en La explicación teleológica, he preferido remitir aquí a dos trabajos previos, de mi autoría, en los cuales desarrollé dicha interpretación. Ésta última, con todo, no dejará de ser explicada, aunque con menor detalle, a lo largo de este mismo trabajo.

${ }^{4}$ La identificación entre función y razón de ser es el error que está en la base de la llamada concepción etiológica del concepto de función. En el caso de la aplicación de esa concepción a la Biología, dicho error cobra la forma de una identificación entre el concepto de función y el concepto de adaptación (Caponi 2010a, p.59).

${ }^{5}$ Si no sospechamos que Monsanto y Bayer actuaron obedeciendo al interés de aumentar la venta de quimioterápicos antitumorales, diremos que sólo fue por un accidente que esos agroquímicos se transformaron en cancerigenos más o menos efectivos.

${ }^{6}$ Al respecto ver: Deléage 1991, p.140, Craig \& Pechmann 2000[1988], p.309; Brewer 1994, pp.325-7; Parrochia 1994, p.95; Begon et al. 2006, p.595.

7 "Eficiencia de consumo: cantidad de energía transferida de un nivel trófico al siguiente" (Lincoln et al. 2009, p.195).

${ }^{8}$ No es la selección natural, por otra parte, la única fuerza que puede incrementar la eficacia de los sistemas ecológicos: la invasión de un ecosistemas por poblaciones de una especie que se aprovecha de algún recurso antes nula o escasamente explotado, también redundará en un incremento de esa eficiencia; y ahí tampoco se hablará de un proceso de diseño.

${ }^{9}$ En varios trabajos anteriores apelé a la noción de ideal de orden natural para establecer comparaciones entre la Historia Natural cuvieriena y la darwiniana (Caponi 2004), para analizar la Teoría de la Selección Natural (2005) y la Biología Evolucionaria del Desarrollo (2010c), y también para establecer comparaciones entre estas últimas (Caponi 2007b; 2008).

Principia 14(3): 349-373 (2010). 
${ }^{10}$ Subrayo que eso lo sabemos después de haber investigado a los seres vivos: la idea de estados privilegiados intrínsecos a los propios seres vivos, es una conclusión, y no un presupuesto, de la investigación fisiológica. En su esfuerzo por explicar cómo el orden de la vida se preserva, la Fisiología encontró esos mecanismos de autorregulación. Mecanismos cuya consideración permite entender mejor cómo es que ese estado privilegiado, ya antes destacado como objetivo explicativo, era alcanzado y sostenido.

${ }^{11}$ El modelo de las margaritas, propuesto por Lovelock (1985, p.65; 1993, p.51) muestra, incluso, como la selección natural puede estar involucrada en esos supuestos mecanismos de autorregulación.

Principia 14(3): 349-373 (2010). 